\title{
Overview of Pharmaceutical Disposal Methods: Addressed to the General Assembly of Illinois
}

\section{Kavitha Chintam ${ }^{1,4^{*}}$,Olivia Williams Barber ${ }^{2,4}$, Suyog Padgaonkar 3,4}

${ }^{1}$ Northwestern University, McCormick School of Engineering, Department of Chemical \& Biological Engineering, Evanston, IL

${ }^{2}$ Northwestern University, McCormick School of Engineering, Department of Civil \& Environmental

Engineering, Evanston, IL

${ }^{3}$ Northwestern University, Weinberg College of Arts \& Sciences, Department of Chemistry, , Evanston, IL

${ }^{4}$ Northwestern University Science and Policy Outreach Task Force, , Evanston, IL

*Authors contributed equally to this work.

http://doi.org/10.38126/JSPG170103

Corresponding author: kchintam@u.northwestern.edu

Keywords: pharmaceuticals; disposal; medications; drug take-back; Illinois.

Executive Summary: Drug donation programs increase medication availability and encourage proper pharmaceutical disposal. Proper disposal decreases the potential human and environmental risk posed by the presence of pharmaceutical compounds in water bodies. Furthermore, the public health hazard of drug abuse is mitigated due to the decreased availability of drugs. The preferred pharmaceutical disposal method is through drug take-back programs, in which medications are returned to local pharmacies, law enforcement, or other responsible agencies. Take-back programs can also involve medication donation, and states such as Oklahoma and Iowa have programs to fill prescriptions for people who would otherwise have financial difficulty. Because the state of Illinois currently does not have an enacted law for the donation and reuse of medication, we propose that Illinois enact clearer laws regarding pharmaceutical disposal and take-back programs.

\section{Statement of issue}

Widespread pharmaceutical use across the country requires consumers to follow proper disposal methods. Proper disposal of pharmaceuticals prevents unintentional poisoning, intentional misuse, health problems from expired products, and environmental contamination through entry into water bodies (U.S. Environmental Protection Agency 2011). Pharmaceuticals accumulate in water bodies from residential sources after they are excreted or flushed and subsequently passed through the wastewater treatment process. Pharmaceuticals are considered contaminants of emerging concerns (CECs) by the Environmental Protection Agency (EPA) due to lack of regulation and the detection of low concentrations in surface water (U.S. Environmental Protection Agency
2019). The impact of residual exposure to active pharmaceutical ingredients (APIs) is difficult to evaluate for both human health and aquatic ecosystems. Many APIs, particularly at high concentrations, are endocrine-disrupting chemicals, which negatively affect wildlife and may also be linked to birth defects and cancer in humans (Guillette and Gunderson 2001, 857-864; Nikolaou, Meric, and Fatta 2007, 1225-1234). While environmental concentrations are not currently high enough to raise concerns of potential harm to human health, further studies are needed to assess this impact (Kostich, Batt, and Lazorchak 2014, 354-359).

According to the Food and Drug Administration (FDA), the preferred method of disposal for most 
medicines is either to follow the disposal instructions provided with the medication or to use a drug take-back option, such as dropping off or mailing in the medication to a designated location (U.S. Food and Drug Administration 2019). Once returned, medication is ultimately incinerated onsite or by qualified vendors (Rudzinski 2012). If a take-back option is not available, medication can either be mixed with dirt and placed in a sealed container with household trash or flushed if the compound is on the FDA flush list (U.S. Food and Drug Administration 2019).

Although flushing all drugs is not promoted, medication on the FDA flush list is potentially harmful if even one dose is taken in a different method than prescribed or through accidental consumption by children or pets (U.S. Food and Drug Administration 2018). Children under six years of age are at the highest risk for unintentional ingestion of medication, which is especially concerning given the increasing number of adult drug prescriptions (Schillie et al. 2009, 181-187; Burghardt et al. 2013, 18-27). Therefore, flushing is recommended for 13 APIs, such as opioids including fentanyl and oxycodone, to reduce the risk of overdose or unintentional use, since nearly $70 \%$ of the 70,237 overdose deaths nationally in 2018 involved opioids (Wilson et al. 2020, 290297). The potential risk for drug abuse is a much greater hazard from a public health perspective than the health and environmental concerns associated with flushing the few medications on the FDA flush list (Khan et al. 2017, 1023-1040). Medications not on the FDA flush list can be thrown away in household trash if take-back is not an option. The FDA recommends mixing the medications with cat litter or coffee grounds to obscure them from children or those intentionally looking for disposed of medications (U.S. Food and Drug Administration 2020). However, this method is not reliable, as the medications are still easily accessible to anyone in the household. Although proper pharmaceutical disposal through flushing or take-back programs is crucial, there is still a large disparity between unused pharmaceuticals and proper disposal.

\section{Political and legal status}

As previously mentioned, there are federal initiatives to make guidelines clearer, such as the
FDA flush list. Additionally, the Drug Enforcement Administration (DEA) hosts a biannual National Take Back Day, which has collected over 6,000 tons of medication since its inception in 2010 (U.S. Drug Enforcement Administration, n.d.). Another nationwide initiative through Walgreens operates over 1,500 disposal kiosks across the United States and has collected over 885 tons of medication since February 2016 (Walgreens, n.d.). Public participation can be high if the collection methods are easy, convenient, inexpensive, and uninterrupted for the consumers (Glassmeyer et al. 2009, 566-572). However, these qualifications can be difficult to meet from an administrative point of view because of challenges including monetary investment, interplay with the regulation of controlled substances, the cost of destruction, and consistency of collection.

Although the enforcement of proper pharmaceutical disposal methods varies across the United States, several state-level programs exist to promote proper pharmaceutical disposal. Donation programs have the potential to benefit both states and consumers. The National Association of Boards of Pharmacy (NABP) has endorsed drug return and reuse programs because of their potential societal benefits, provided they meet certain quality and safety requirements (Klein et al. 2012).

Some programs use returned medication as a resource to promote equal access to medication across income levels. One nursing home take-back program in Tulsa County, Oklahoma filled over 250,000 prescriptions between its inception in November 2004 through January 2020 with an average wholesale price of nearly $\$ 25.5$ million (Tulsa County Medical Society, n.d.). The program provides prescriptions for low-income citizens free of charge (Johnston 2015). Another donation program, SafeNetRx, provides medication to Iowans who are uninsured, underinsured, or at or below $200 \%$ of the federal poverty level. The program served over 70,000 people between 2007 and 2016 (SafeNetRX, n.d.). Programs to promote affordability should be a priority in the United States, where one-quarter of adults find the cost of prescriptions "difficult" to cover (Kirzinger et al. 2019). 
Although 38 states have enacted laws for the donation and reuse of medication, many do not have operational programs (Cauchi and Berg 2018). Illinois tracks how medications are dispensed through the Prescription Monitoring Program (PMP), but it does not have any laws concerning medication donation (Illinois Department of Human Services, n.d.). Also, data collected from the PMP is not used to compare the disposal of medication, which could help evaluate the efficacy of statewide take-back programs. For example, a study of five Kentucky counties used PMP data and found that take-back events did not have a great impact on reducing the availability of controlled medication since only around $0.3 \%$ of the estimated dispensed medications were collected (Egan et al. 2017, 69-77). This inefficiency was traced to a lack of awareness, so a possible increase in the rate of drug collection could be achieved by implementing education programs.

\section{Policy options}

i. Option 1: Enact laws for donation and reuse of medication

Clearly-written pharmaceutical disposal laws would mandate Illinois-specific guidelines and tracking to be in place. Parts of a "Pharmaceutical Disposal Bill" would include the following:

- Establish proper donation guidelines, such as which medications can be donated, where these donations can be dropped off, and educate the public on these guidelines at the time of medication pick-up at the pharmacy

- Establish demographics who are eligible for donated medications to promote the distribution of medications to uninsured or economically disadvantaged people

- Require tracking of pharmaceutical disposal through the PMP system to account for the entire lifecycle of a drug

\section{Advantages}

These laws would allow for clear guidelines on donating medication and educating the public on these guidelines to promote proper disposal efforts. Furthermore, to prevent the unnecessary distribution of dangerous drugs and reduce the likelihood of drug abuse, acceptable medications, and eligible donation-receiving populations would be specified. Using data from the PMP would allow programs to determine their impact on removing excess medications from public circulation. Disadvantaged communities in need of certain medications would have increased access to affordable care.

\section{Disadvantages}

The lack of an incentive for donating medication may decrease the total number of participants. The ease of accessibility of donating may also determine the success of these laws. Staff will have to sort through medications and send expired or contaminated drugs for incineration, which may expose them to the risk of injury from unauthorized disposals such as needles. This risk can be mitigated by ensuring that upfront sorting is performed. The cost of the program may also be a disadvantage but may be outweighed by the presumed lower public health costs, which could be confirmed by a cost-benefit analysis.

\section{ii. Option 2: Increase education on disposal practices at local levels}

The state of Illinois would provide funding to local communities to increase education on proper disposal practices. These educational programs would also cover the importance of preventing drug abuse and identifying proper disposal techniques. Patients could be educated through the following pre-existing channels:

- Pharmacists informing patients about returning unwanted medication as their prescription is dispensed

- Local governments increasing awareness through social media campaigns

\section{Advantages}

Educational outreach would allow the public to consider the act of taking back medication an action the public can take throughout the year. This strategy would be less resource-intensive than creating additional programs and would increase the use of take-back initiatives and drop off locations already in place.

\section{Disadvantages}

Laws would have to be enacted to clarify processes and responsible parties, which would delay 
implementation. The disposal of valuable unused medication would continue in a country where many people struggle to afford healthcare. There may be an initial increase in returned medication, but interruptions in outreach or unresolved accessibility issues may result in consumers continuing to discard medication incorrectly.

\section{iii. Option 3: Inaction}

Inaction would involve keeping the same degree of standards for pharmaceutical disposal in Illinois.

\section{Advantages}

There would be no reallocation of funds for a statewide take-back program. Also, the logistics and politics related to either Options 1 or 2 would be avoided.

\section{Disadvantages}

Improper pharmaceutical disposal would continue to be widespread in Illinois, resulting in environmental and public health hazards. Valuable unused pharmaceuticals would be sent to landfills or incinerated rather than given to those struggling to afford the medication that would increase their quality of life.

\section{Policy recommendation}

We recommend policy Option 1. Establishing clear guidelines and laws would increase the likelihood of proper pharmaceutical disposal. Prioritizing the prevention of drug abuse and water contamination would make these laws a vital part of Illinois legislation. Tracking what should be a closed-loop

\section{References}

Burghardt, L. C., J. W. Ayers, J. S. Brownstein, A. C. Bronstein, M. B. Ewald, and F. T. Bourgeois. 2013. "Adult prescription drug use and pediatric medication exposures and poisonings." Pediatrics 132 (1): 18-27. https://doi.org/10.1542/peds.2012-2978. https://www.ncbi.nlm.nih.gov/pubmed/2373 3792.

Cauchi, R., and Berg, K. 2018. "State Prescription Drug Return, Reuse and Recycling Laws." https://www.ncsl.org/research/health/stateprescription-drug-return-reuse-andrecycling.aspx. process from pharmaceutical dispensing to disposal would provide more accurate rates of proper pharmaceutical disposal. Option 1 would also allow Illinois to be a leader in proper pharmaceutical disposal in the United States.

While Option 2 would increase awareness of correct disposal practices, it would take time and organization to properly implement. The educational component would be highly beneficial if it were instead incorporated into a larger pharmaceutical disposal effort. Emphasizing the importance of proper disposal at the time of purchase would increase the longevity of medications. Counseling patients on drug disposal has been shown to significantly increase proper disposal in other states (Seehusen and Edwards 2006, 542-547; Yanovitzky 2017, 590-597). Furthermore, implementing the laws explained in Option 1 would provide the basis for possible educational efforts. Option 2, therefore, could be implemented after laws have been established.

Ideally, both Options 1 and 2 would be implemented in tandem, but at minimum, enacting pharmaceutical disposal laws would allow for basic rules to be established before adding an educational component. Putting proper pharmaceutical disposal at the forefront of legislators' agendas would empower communities to prioritize their health and the environment while making Illinois a safer, cleaner state.

Egan, K. L., E. Gregory, M. Sparks, and M. Wolfson. 2017. "From dispensed to disposed: evaluating the effectiveness of disposal programs through a comparison with prescription drug monitoring program data." Am J Drug Alcohol Abuse 43 (1): 69-77. https://doi.org/10.1080/00952990.2016.124 0801.

Glassmeyer, S. T., E. K. Hinchey, S. E. Boehme, C. G. Daughton, I. S. Ruhoy, O. Conerly, R. L. Daniels, L. Lauer, M. McCarthy, T. G. Nettesheim, K. Sykes, and V. G. Thompson. 2009. "Disposal practices for unwanted residential medications in the United States." Environ Int 35 (3): 566572 . https://doi.org/10.1016/j.envint.2008.10.007 
Guillette, L. J., Jr., and M. P. Gunderson. 2001. "Alterations in development of reproductive and endocrine systems of wildlife populations exposed to endocrine-disrupting contaminants." Reproduction 122 (6): 857-864. https://doi.org/10.1530/rep.0.1220857.

Illinois Department of Human Services. "Illinois Prescription Monitoring Program." Illinois Prescription Monitoring Program. https://www.ilpmp.org/PMP brochure.pdf.

Johnston, L. 2015. "Poor Residents Benefit From Oklahoma County's Medicine Recycling." Interview by Steve Inskeep. Radio. Morning Edition, NPR, May 22, 2015. https://www.npr.org/2015/05/22/40868006 5/poor-residents-benefit-from-oklahomacountys-medicine-recycling .

Khan, U., R. A. Bloom, J. A. Nicell, and J. P. Laurenson. 2017. "Risks associated with the environmental release of pharmaceuticals on the U.S. Food and Drug Administration "flush list"." Sci Total Environ 609: 1023-1040. https://doi.org/10.1016/j.scitotenv.2017.05.2 69.

Kirzinger, A., L. Lopes, B. Wu, and M. Brodie. 2019. “KFF Health Tracking Poll - February 2019: Prescription Drugs." KFF. Kaiser Family Foundation. https://www.kff.org/healthcosts/poll-finding/kff-health-tracking-pollfebruary-2019-prescription-drugs/.

Klein, R., L. Anderson, P. Burgess, T. D'Antonio, B. Fry, B. Goetz, S. Kedron, N. Penny, J. Tipton, E. G. McGinley, E. Lewalski, S. Fowle, E. Shaffer, and D. Zak. 2012. Report of the Task Force on Drug Return and Reuse Programs. Mount Prospect, IL: National Association of Boards of Pharmacy. https://nabp.pharmacy/wpcontent/uploads/2016/07/Drug-Return-andReuse-Programs-TF-Report-Final.pdf.

Kostich, M. S., A. L. Batt, and J. M. Lazorchak. 2014. "Concentrations of prioritized pharmaceuticals in effluents from 50 large wastewater treatment plants in the US and implications for risk estimation." Environ Pollut 184: 354-359. https://doi.org/10.1016/i.envpol.2013.09.013.

Nikolaou, A., S. Meric, and D. Fatta. 2007. "Occurrence patterns of pharmaceuticals in water and wastewater environments." Anal Bioanal Chem 387 (4): 1225-1234. https://doi.org/10.1007/s00216-006-1035-8.

Rudzinski, S. 2012. "Recommendation on the Disposal of Household Pharmaceuticals Collected by TakeBack Events, Mail-Back, and Other Collection Programs." Official memorandum. Washington, DC: U.S. Environmental Protection Agency. https://rcrapublic.epa.gov/files/14833.pdf.
SafeNetRX. n.d. "Iowa Drug Donation Repository: 2016 Performance

http://safenetrx.org/wpcontent/uploads/2017/04/2016Performance-Update-Drug-DonationRepository-brochure.pdf.

Schillie, S. F., N. Shehab, K. E. Thomas, and D. S. Budnitz. 2009. "Medication overdoses leading to emergency department visits among children." Am J Prev Med 37 (3): 181-187. https://doi.org/10.1016/i.amepre.2009.05.01 8.

Seehusen, D. A., and J. Edwards. 2006. "Patient practices and beliefs concerning disposal of medications." J Am Board Fam Med 19 (6): 542547. https://doi.org/10.3122/jabfm.19.6.542. https://www.ncbi.nlm.nih.gov/pubmed/1709 $\underline{0787 .}$.

Tulsa County Medical Society. n.d. "Drug Recycling - Utilization of Unused Prescription Drugs Act." http://tcmsok.org/drug-recycling/ U.S. Drug Enforcement Administration. n.d. "Take Back Day." https://takebackday.dea.gov/.

U.S. Environmental Protection Agency. 2011. How to Dispose of Medicines Properly. EPA 816-F-11003.

https://www.epa.gov/sites/production/files/ 2015-06/documents/how-to-disposemedicines.pdf.

U.S. Environmental Protection Agency. 2019. "Contaminants of Emerging Concern Including Pharmaceuticals and Personal Care Products." https://www.epa.gov/wqc/contaminantsemerging-concern-including-pharmaceuticalsand-personal-care-products.

U.S. Food and Drug Administration. 2018. "Drug Disposal: Flush Potentially Dangerous Medicine."

https://www.fda.gov/drugs/disposal-unusedmedicines-what-you-should-know/drugdisposal-flush-potentially-dangerousmedicine.

U.S. Food and Drug Administration. 2019. "Disposal of Unused Medicines: What You Should Know." https://www.fda.gov/drugs/safe-disposalmedicines/disposal-unused-medicines-whatyou-should-know.

U.S. Food and Drug Administration. 2020. "Where and How to Dispose of Unused Medicines". https://www.fda.gov/consumers/consumerupdates/where-and-how-dispose-unusedmedicines.

Walgreens. n.d. "Safe medication disposal." https://www.walgreens.com/topic/pharmacy Lsafe-medication-disposal.jsp. 
Wilson, N., M. Kariisa, P. Seth, H. th Smith, and N. L. Davis. 2020. "Drug and Opioid-Involved Overdose Deaths - United States, 2017-2018." MMWR Morb Mortal Wkly Rep 69 (11): 290-297. https://doi.org/10.15585/mmwr.mm6911a4. https://www.ncbi.nlm.nih.gov/pubmed/3219 $\underline{1688}$.
Yanovitzky, I. 2017. "A Multiyear Assessment of Public Response to a Statewide Drug Take-Back and Disposal Campaign, 2010 to 2012." Health Educ Behav 44 (4): 590-597. https://doi.org/10.1177/1090198116682433

Kavitha Chintam is a Ph.D. student in the Seitz lab in the Chemical \& Biological Engineering Department at Northwestern University. She performs research in electrochemical carbon dioxide/monoxide reduction and is a passionate advocate for mitigating climate change. Kavitha believes that sound science policy is critical to implement tangible change which benefits everyone, particularly vulnerable communities.

Olivia Williams Barber is an environmental engineering Ph.D. student in the Civil and Environmental Engineering Department at Northwestern University. Her research in the Hartmann lab focuses on the anthropogenic contribution to antimicrobial resistance. Although scientific progress that is beneficial to society often originates in research and labs, Olivia sees the implementation and lasting changes to our lives as a product of policy.

Suyog Padgaonkar is a graduate student pursuing his Ph.D. in chemistry at Northwestern University. His research focuses on how the properties of nanomaterials change in response to light and his interest in science policy stems from his desire to combat misinformation.

\section{Acknowledgements}

We would like to acknowledge the entire Legislative Outreach Team in SPOT, as well as the broader organization, for their support and continued dedication to bring thorough science to policymakers and the public. This memo was inspired by a specific request from our one-pager program for Illinois legislators. We thank everyone, especially Jamie Neely and Chamille Lescott, who has aided us in making these connections and being a part of the conversation. 